\title{
Entry Point for China's Climate Policy
}

\author{
Yunchen $\mathrm{Li}^{1, \dagger}$, Zhongyue $\mathrm{Li}^{2, *,}$, Jianing Zhou ${ }^{3, \dagger}$ \\ ${ }^{I}$ Birmingham Business School, The University of Birmingham, Birmingham, B15 2TT, United Kingdom \\ ${ }^{2}$ Thurgood Marshall College, University of California San Diego, La Jolla, California, 92093, United States \\ ${ }^{3}$ College of Letters and Science, University of California, Davis, Davis, California, 95616, United States \\ "Corresponding author. Email: ${ }^{2}$ zhl081@ ucsd.edu \\ ${ }^{\dagger}$ Those authors contributed equally.
}

\begin{abstract}
China is the world's biggest emitter of greenhouse gases and one of the countries confronting global warming problems, such as air pollution and water shortage. Carbon taxing is a fee levied on companies that burn coal, oil or gas to reduce greenhouse gas emissions. The purpose of this study is to figure out the impact of the carbon tax on China. The carbon tax is not completely beneficial to China, and there are still some disadvantages to the carbon tax. Among them, the increase in energy prices is a challenge and a heavy burden for some households in China. This article continues the previous study by using CEEPA to simulate China's carbon tax to study how a carbon tax can alleviate carbon dioxide and how it affects the development of reducing the gap between urban and rural areas and improving people's living standards. This article used the SWOT model predicting the strengths, weaknesses, opportunities and threats of the carbon tax in China in aspects of macroeconomics, social welfare and global climate change. The article also discussed the current climate policy related to carbon emissions implemented by the Chinese government. Through a combination of CEEPA and SWOT research, it is known that a carbon tax will not have a positive impact on China. The carbon tax will increase the gap between the rich and the poor in China and cause an increase in commodity prices. Therefore, this article recommends that China abolish the carbon tax to avoid widening the gap between China's rich and the poor.
\end{abstract}

Keywords: Carbon pricing, China, Poverty, Redistributing carbon revenues, Climate policy

\section{INTRODUCTION}

Global climate deterioration and global warming are a crucial problem that needs to be solved in recent years. Human burns fossil fuels and releases these greenhouse gases into the air. In 2019, atmospheric levels of carbon dioxide, which is the largest proportion of greenhouse gases, reached the highest level ever recorded. Higher levels of carbon dioxide in the air contribute to global warming. Global warming may negatively impact our daily lives, such as water shortage, higher sea levels, and increased fire threats [1]. China is the world's largest emitter of greenhouse gases, emitting more than a quarter of the world's total each year. In 2005, China surpassed the United States as the world's largest emitter of greenhouse gases. The health and livelihoods of the Chinese people are threatened by air pollution, water shortages, and soil pollution [2]. To deal with this problem, some people argue that carbon taxing could reduce greenhouse gas emissions. A carbon tax is a fee levied on businesses and individuals that amounts to a "pollution tax" levied on companies that burn carbonbased fuels such as coal, oil, gasoline, and natural gas. The government could charge people for emitting greenhouse gases. Carbon taxing is an economic signal that polluters decide whether to stop polluting and cut emissions or continue polluting and pay for it [3]. Therefore, the overall environmental objective can be achieved most flexibly and cost-effectively in society. Carbon taxing would also spur clean technology and market innovation and provide new low-carbon power for economic growth.

There have been many researches on carbon taxing before, including applying carbon taxing to improve air quality, carbon pricing and income inequality, the economic impact of interacting carbon pricing and renewable energy policy in China and coordinating carbon pricing policy and renewable energy policy with a case study in China. Research on improving air quality through carbon taxes has found that carbon taxes can reduce air pollution and adverse effects on humans. 
Depending on the health assessment chosen, the national health co-benefits of improving air quality will offset some or all of the policy costs. As the policy becomes more stringent, the net health co-benefits will become greater [4]. These studies focused on some specific sides of carbon taxing, and they do not have a well-rounded analysis of the impact of carbon taxing. They just studied air quality, economic impact, or income impact, which is not enough. In addition, although there are many studies about carbon taxing, as more and more countries apply carbon taxing to reduce greenhouse gases, this is a burden of poverty since the price of energy and food may increase significantly. People who live in poverty cannot maintain their daily life since anything related to using gas would increase their price, which negatively impacts society, especially for a country with a large number of poor people. Most studies have found that such policies would be regressive, with a greater burden (relative to income or other measures) on low-income families than highincome families. As an example of China, people who live in poverty get less than $\$ 730$ each year, and the daily income is only $\$ 2$. For people who belong to a low-income family, their daily income is $\$ 2-\$ 10$, which is not so much [5]. Thus, If the government applied carbon pricing on those families, the expenditure would increase significantly. In addition, for countries with a large portion of poverty, their Gini coefficient and Engel's coefficient tend to be very high, which means many people live in poverty, so carbon taxing may significantly impact their daily lives. In this way, applying carbon taxing may put an economic burden on the people who live in poverty and cannot afford their basic needs. Hence, it is important to develop a comprehensive approach to implementing carbon taxing in the real world.

In this term, the research question of this study is: what is the impact of carbon tax have on China? By studying this issue, the paper would have a better understanding of the impact of carbon tax on China's economy, so as to rectify related problems more reasonably in the future and make up for its shortcomings while developing the economy better. China is one of the developing countries with a large scale of people who live in poverty, and China is also confronting the greenhouse gas emission problem. Also, the Chinese government has applied carbon taxing in some places. This study will analyze the outcome of these cases. This study wants to study the impact of carbon taxing to evaluate this method deeply. This study tries to determine the impact of carbon taxing on society, government, environment, people, animals, etc. Hence, whether to impose a carbon tax and how to implement it effectively will be figured out. Therefore, as a developing country, China may know how to apply carbon taxing in society and fully play on its strengths. Based on the information and studies before, this study assumes that this positively impacts household distribution in China, like shortening the gap between the rich and the poor. In order to verify the assumption, this study will analyze the data and information through these few steps. First, through the literature review method, this study will analyze the impact of carbon taxes on income distribution, socioeconomic and interregional capital flows in China. Second, through the quantitative method, the carbon tax as the research object for research and analysis. Finally, the conclusions based on household expenditure and economic development in China, which can further verify the hypothesis of this study. Based on the conclusion, reasonable suggestions are given to the impact of carbon taxing in China.

\section{LITERATURE REVIEW}

\subsection{China's Carbon Tax and the CEEPA Model}

In 2007, Mark Brenner et al. published a paper on the impact of carbon taxes on China's distribution. In the paper, they stated that China's levying of carbon fees on the use of fossil fuels would have a gradual impact on income distribution [6]. Their research shows that the sharp contrast between the diminishing distributional effects of the carbon tax fee research is driven by the difference between urban and rural expenditure patterns. They used a new distribution model-sky trust. This distribution model helps reduce the consumption of fossil fuel combustion while increasing income equality. In 2012, Q and Y also studied how a carbon tax can alleviate carbon dioxide and how it affects the development of reducing the gap between urban and rural areas and improving people's living standards. This paper uses the CEEPA model to simulate China's carbon tax. Different carbon tax plans were designed in the model. Their effects on household disposable income, household welfare, economic growth, and carbon dioxide emissions were compared [7]. Through research, it shows that if the current policy is biased towards urban households in the social security system and the current investment-driven economic growth model, if there is no supplement to its family protection measures, the carbon tax will widen the gap between urban and rural areas and reduce the family's living standards. Over time, the impact of carbon taxes will be further expanded. However, regardless of emission intensity or overall control targets, a specific carbon tax should be reduced. In 2013, Qiaomei Liang led her team to use the CEEPA model to study the impact of China's carbon tax on households with different incomes. The content again pointed out that carbon tax will widen the income and welfare gap between urban and rural areas and widen the income and welfare gap within urban groups [8]. On this basis, it is shown that if carbon tax revenue is used to reduce 
indirect taxes, while appropriately increasing government transfer payments to rural households and urban disadvantaged groups can alleviate the deterioration of distribution caused by the carbon tax and reduce the negative impact on household life of all income groups.

\subsection{China's Carbon and Households with Different Incomes}

In contrast, they are maintaining emissions reductions and minimizing the overall socioeconomic impact. The paper published by Yazid Dissou et al. expresses the distributional impact of the carbon tax from another aspect. The impact of the carbon tax on commodity prices ignores the impact of factor price changes on personal welfare. However, the salary of capital and labor will not be affected by these taxes. Therefore, the share of income in each household is not consistent [9]. The value provided by this paper is decomposed by analyzing the incidence of unequal carbon taxes in terms of changes in individual welfare indicators. At the same time, this thesis also uses the Lorentz and concentration curve and the Gini index to develop a general equilibrium model to evaluate the impact of carbon taxes on commodity prices to extend the impact of its distribution on households. The results show that the traditional method of assessing the impact of carbon taxes on inequality may be misleading if only the price of commodities is used. The results reveal the desirability of using these two channels when assessing unequal carbon taxes.

In 2018, Youxia Guo proved that carbon taxes are diminishing in urban and rural areas, and the decline in rural areas is significantly higher than that in cities [10]. This also shows that the consumption expenditure of low-income groups for income is much higher than that of high-income groups. Thus, rural spending far exceeds urban spending. In 2020, Wu et al. analyzed the government's policies and emission reduction measures from another perspective. This paper uses the CGE model to study the economic impact of implementing the national carbon market and renewable energy subsidies in China's power sector [11]. The results show that if the carbon pricing mechanism is in place, renewable energy policies will increase the economic cost of reducing greenhouse gas emissions and lead to a decline in carbon price levels. Combining the two policies is gradually achieving emission reduction targets and the continued promotion of renewable energy. Although the emissions trading scheme is necessary for effective emission reduction, renewable energy policies can promote the large-scale use of renewable energy in the power sector. In addition, the adoption of renewable energy policies may result in a large amount of cross-regional capital flowing into the central and western regions. This will increase low- carbon investment in underdeveloped regions, which is consistent with the content of this study.

Finally, through adjustments to renewable energy, the impact of carbon taxes on households with different incomes and the climate is improved.

\subsection{Conclusion}

From these papers, it can be seen that China's emission reduction efforts and actions play a pivotal role in the global response to climate change. The carbon tax effects are a crucial issue affecting the public acceptance of emission reduction policies and, therefore, whether the policies can be smoothly implemented. For China, which is undergoing a transition period and has a severe social gap between the rich and the poor, assessing the income distribution effect of the carbon pricing mechanism is very important. For China's green emissions and shorten the gap between rich and flawed due to carbon tax. This research will focus more on achieving emission reduction targets and the predicted effects of the carbon tax in China. Then, it will suggest whether implementing a carbon tax in China or not.

\section{METHOD}

\subsection{Research Design}

The SWOT analysis method has been used to analyze the anticipated impacts of the carbon tax in China. The article includes predictions and projections of various strengths (S), weaknesses (W), opportunities $(\mathrm{O})$, threats $(\mathrm{T})$, and other factors that carbon tax may have. It comprehensively, systematically, and accurately describes the scenario in which this topic is located. By listing the 4 aspects related to carbon tax with SWOT analysis, researchers may better understand government regulations and environmental policies. These findings should provide a valuable reference to assess and evaluate the anticipated impacts of carbon in China.

\subsection{China's Climate Policy}

In China's climate policy, many problems can be solved with only one policy. This policy is a carbon tax. The carbon tax is an upstream tax levied on the supply of carbon in fossil fuels. This policy can significantly reduce greenhouse gas emissions, and at the same time, alleviate the government's financial worries in this regard and promote a green and low-carbon life. As the country with the most significant carbon dioxide emissions globally, the emergence of a carbon tax has bluntly and shared the pressure on China caused by this part. However, the carbon tax is not entirely beneficial to China, and there are still some disadvantages to the carbon tax. The increase in energy prices is a challenge and a heavy burden for some households in China. 
However, as China continues to transition to a sustainable growth model, it can prove that a carbon tax can be a robust policy that can support economic rebalancing and improve the environment.

\subsection{SWOT}

\subsubsection{Strength}

\subsubsection{Ease the Increasing Temperature in China}

The research conducted by China's Ministry of Science and Technology showed that the average temperatures across China rose from 0.9 to $1.5^{\circ} \mathrm{C}$ from 1909 to 2011. This trend will further intensify in the future, and temperatures across most of China will rise another 1.3 to $5.0{ }^{\circ} \mathrm{C}$ by the end of this century compared to the global average of 1.0 to $3.7^{\circ} \mathrm{C}$ [12]. In recent years, there have been signs showing global warming is accelerating. It is necessary to ease the rising temperature in China as soon as possible. A carbon tax may influence the speed of carbon emissions and then ease the increasing temperature in China. Consequently, it will bring a more moderate living environment to Chinese people.

\subsubsection{Accelerating the Pace of China's Energy Transition}

Implementing a carbon tax may accelerate the pace of China's energy transition. Although in 2019, coal still accounted for $57.7 \%$ of China's energy consumption, the Chinese government still promised that China will scale up its Intended Nationally Determined Contributions by adopting more vigorous policies and measures, and aim to have $\mathrm{CO}_{2}$ emissions peak before 2030 and achieve carbon neutrality before 2060 [13]. To realize carbon emissions peak and achieve carbon neutrality, coal consumption needs to be greatly reduced in the future.

China also has abundant renewable energy resources to replace fossil fuels when its price rises because of carbon taxation. The theoretical capacities of wind energy resources at $80 \mathrm{~m}$, solar energy and hydro-power energy resources that can be developed technologically in China are 3.5 billion kilowatts, more than 5 billion kilowatts and approximately 690 million kilowatts, respectively [13]. The reserves of renewable energy resources can support China's energy transition.

\subsubsection{Weakness}

\subsubsection{Lower Consumption in Domestic Market}

A carbon tax will raise the price of carbon-based energy sources. Unfortunately, carbon emissions are from nearly all the sectors in daily life. A carbon tax may raise the prices of goods in many sectors inevitably. Higher prices are connected with lower consumption in many countries and lower prices with higher consumption (Figure 3). Consequently, applying a carbon tax may lower domestic consumption.

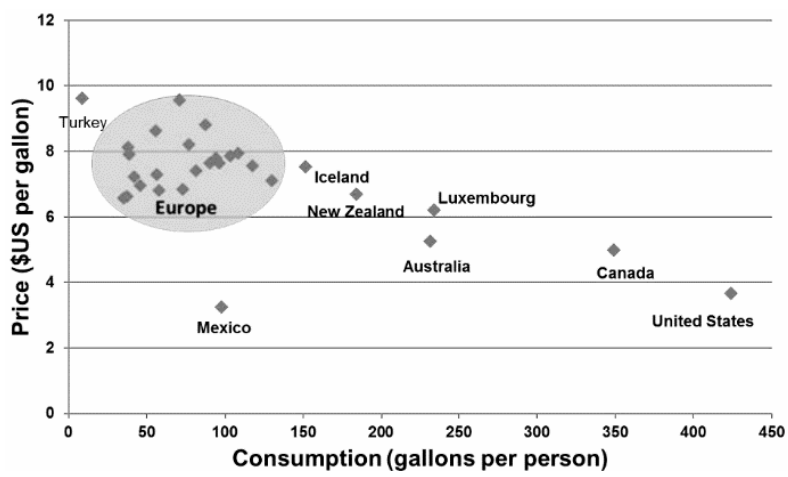

Figure 1 Gasoline Price Versus Consumption in Industrial Countries, 2012 [14].

\subsubsection{Negative Effects of the Carbon Tax on Low- Income Households}

Based on the results of Figure 4, people who live in poverty get less than $\$ 730$ each year, and their daily income is only $\$ 2$. For people who belong to a lowincome family, their daily income is $\$ 2-\$ 10$, which is insufficient to support themselves. Many products are related to energy because their production process requires energy. Thus, If the government applied carbon pricing on those families, the expenditure would increase significantly, for the family who belongs to low-income and poor could not maintain their daily lives.

Table 1 Breakdown of Class Income Brands

\begin{tabular}{lll}
\hline Income Brand & Daily Income & Annual Income \\
\hline Poor & $<\$ 2$ & $<\$ 730$ \\
Low & $\$ 2-\$ 10$ & $\$ 730-\$ 3650$ \\
Lower-middle & $\$ 10-\$ 20$ & $\$ 3650-\$ 7300$ \\
Upper-middle & $\$ 20-\$ 50$ & $\$ 7300-\$ 18250$ \\
High & $>\$ 50$ & $>\$ 18250$ \\
\hline
\end{tabular}

It can be seen from Figure 5 that Engel's coefficient gradually decreased from 2003 to 2019 in the rural area. Engel's coefficient decreases from nearly 70 percent to nearly 30 percent. Based on the United Nations, the coefficient above 59 percent means poverty, 30 percent to 40 percent means a good standard of living. The rural residents in China are living at a good standard now. However, for figure 6, although the Gini coefficient decreases from 0.491 to 0.465 , it is still higher than 0.4 , which means the degree of inequality is relatively high. In addition, according to figure 7 , people living below the international poverty line is 0.7 million in 2015, which is approximately 0.5 percent of the population in China. Therefore, if the government applies carbon pricing in the market, the people who live in poverty 
may face severe financial pressure. Since many goods and services are energy-related, a significant portion of consumption expenditure would be affected if governments adopted carbon pricing. For food, tobacco and liquor, the factory needs the energy to run the machine to make the product. The expenditure of residence will be directly affected by carbon pricing since electricity and gas will increase. Another part of the expenditure will be affected by carbon pricing because they need electricity to maintain the basic operation of the workplace (see Figure 3).

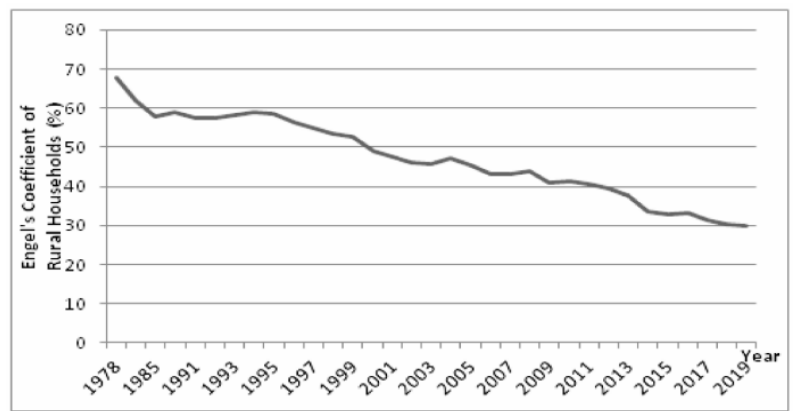

Figure 2 The change of family Engel coefficient of rural residents in China [15]

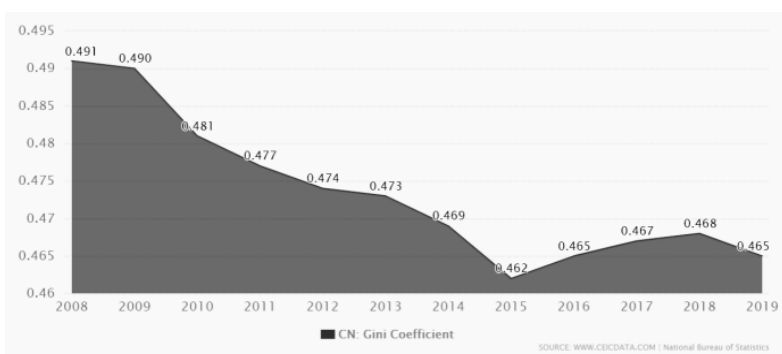

Figure 3 China's Gini coefficient from 2008 to 2019 [16].

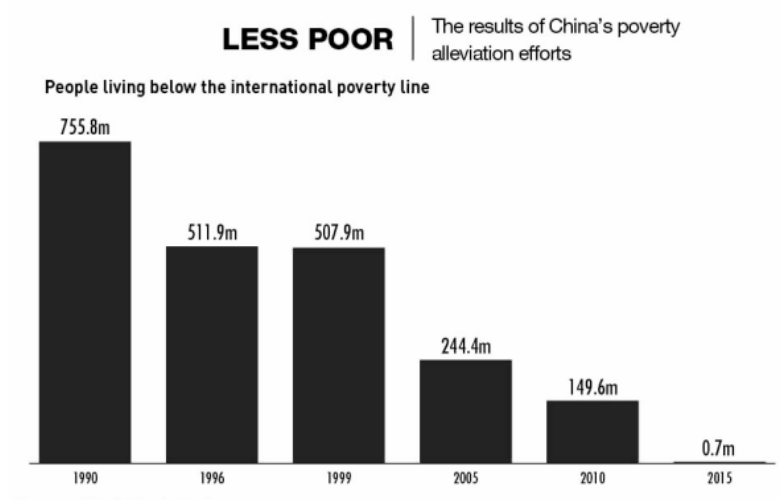

ources: World Bank, Statist

Figure 4 The percent of people living below the international poverty line in China from 1990 to 2015 [17].

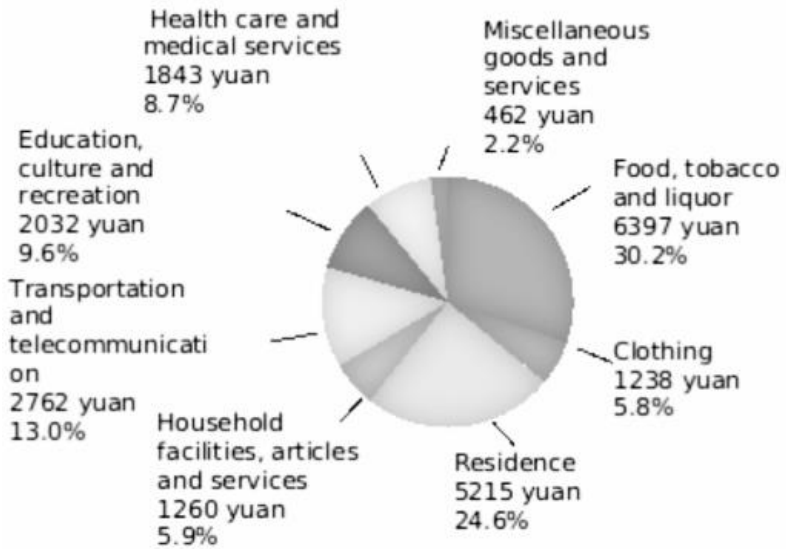

Figure 5 National Per Capita Consumption Expenditure and Composition in 2020 [18].

\subsubsection{Opportunity}

China accounted for the largest percentage of total carbon dioxide emissions worldwide, with $29 \%$ of carbon dioxide emitted (see Figure 6).

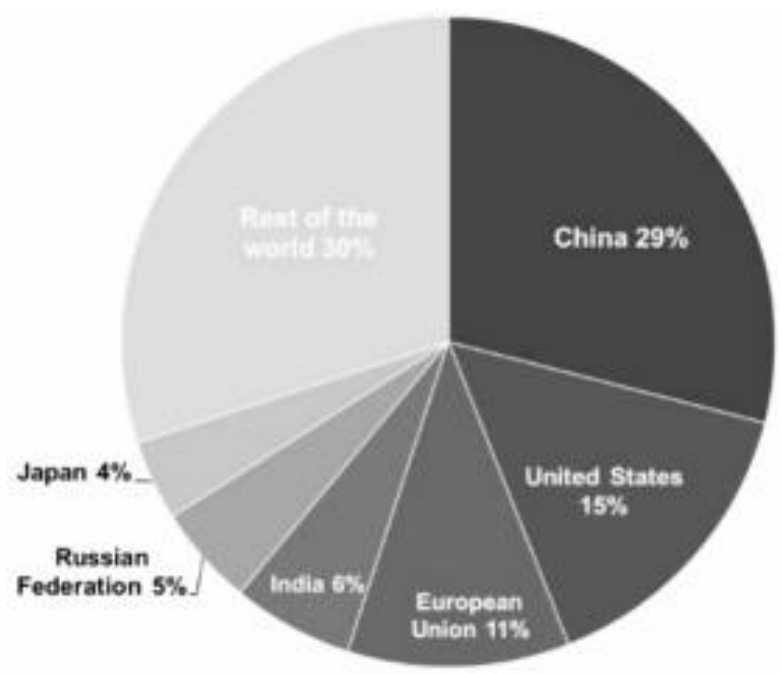

Figure 6 Percentage of Global CO2 Emissions by Country/Region [19].

The Paris Agreement is the first global climate change agreement related to carbon emission that contains policy obligations for countries worldwide. This agreement aims to reduce carbon emissions. China is one of the contracting parties. A carbon tax may help China in reducing carbon emissions and then improving its national image.

A carbon tax may affect people's driving by raising the price of different fossil fuels, particularly gasoline. In the long-term, people are more responsive to gasoline price increases, as they have to purchase different vehicles such as electric vehicles and adjust their driving habits.

After carbon taxation was implemented in the USA, electric vehicle (EV) sales increased sharply. Some electric car manufacturers and their suppliers suddenly 
appear on the horizon. The Tesla corporation surpassed Toyota and Volkswagen, becoming the most valuable car company in the world. In the meantime, the rising production of batteries and chips used in electric vehicles has also creating GDP and jobs in the United States.

In China, by implementing a carbon tax, the pace of the development of the electric vehicle industry would increase. China's annual plug-in electric vehicle (PEV) sales surpassed the USA in 2015 (see Figure 7). It means that China has larger demand for electric vehicles than the USA. So, the carbon tax may force China to accelerate its energy transition and allow China to develop its electric vehicle industry. Most countries without carbon tax may not gain this opportunity to develop their electric vehicle industry.

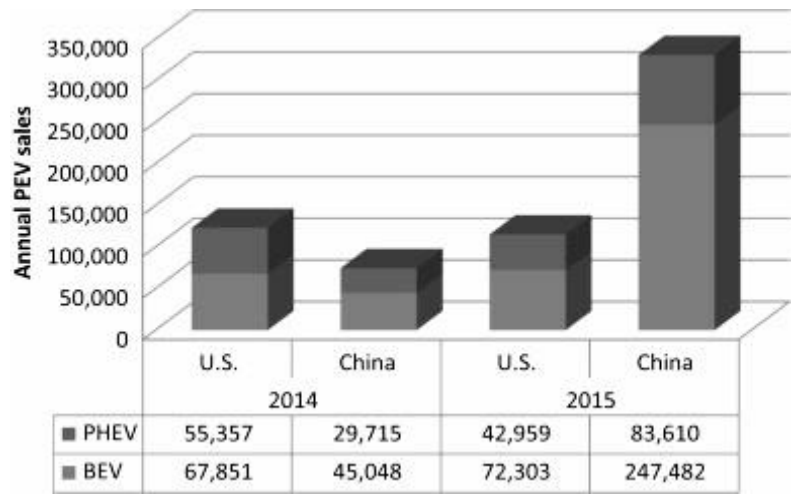

Figure 7 China and U.S. PEV Sales [20].

\subsubsection{Threat}

The carbon tax will increase the price of domestic products. Till recently, only several countries have implemented a carbon tax, such as the Netherlands, Denmark and the USA. As for the import market, when China is trading with other countries, most countries sell goods without the carbon tax. Suppose the price of the same products is lower in other countries. China would import more goods but not exporting them. Also, the export market of high-carbon products is forced to shrink as the export cost increases and their competitiveness weakens. More and more Chinese companies and foreign companies who have plants in China will produce fewer goods. China will lose absolute advantages and even comparative advantages in many fields. Consequently, the net export would decrease after implementing the carbon tax.

Since China is an export-oriented economy, the decrease in exports will directly affect the development of China's economy and even has negative effects on the employment rate.

\section{RESULTS}

Based on the above SWOT analysis, it is predicted that carbon taxation may have both positive and negative impacts in China. Positive impacts include Ease the Increasing Temperature in China, changing the mobility of Chinese households to a more environmental-friendly Way, accelerating the pace of China's energy transition. However, applying carbon tax is projected to have severe negative impacts: the lower consumption in the domestic market and the income of poor households in China. It may also decrease net export and slow down the economic growth of China.

\section{DISCUSSION}

From the analysis and results, it can be seen that carbon tax is a double-edged sword policy. Although it can improve the overall natural environment in the long term, from the perspective of human society, it cannot solve basic economic problems in the short term and increases the burden of poor families. Specifically, a carbon tax will have a negative impact on China's trade, especially for those countries that have not yet implemented a carbon tax. In addition, carbon taxes are unfair to different income groups in China. In this case, poor households, especially those living in rural areas, will be most affected by the carbon tax. Therefore, a carbon tax is not suitable for a country like China. In general, although carbon tax may have several positive effects in China, the disadvantages of predicted effects outweigh the advantages.

In this article, only one model has been implemented, that is SWOT. The SWOT analysis method lists the main internal strengths and weaknesses and the external opportunities and threats closely related to the carbon tax. However, SWOT could only be used to do qualitative research. This article only predicted some possible impacts of the carbon tax is implemented in China but not the degree of the impacts of the carbon tax. For future study, econometric regression models could analyze how deep those impacts of the carbon tax are in China.

\section{CONCLUSION}

Based on the research background that China is the world's largest emitter of greenhouse gases and Chinese people are suffering from a series of problems brought about by global warming, the impact of the carbon tax on China as a solution to reduce greenhouse gas emissions was studied. This study reviewed some theories and information that people purposed before. First, some people stated that carbon taxing is a useful policy since it can improve the environment and narrow the gap between rich and poor as China develops. Second, some scientists proposed that if governments can use carbon taxes to reduce indirect taxes and 
increase transfer payments to vulnerable groups, it will reduce the negative impact on people from different income groups. Third, many people deem that carbon taxing can reduce greenhouse gas emissions and diminish the overall socioeconomic impact. Then, this study analyzed carbon tax in detail through a SWOT (Strength, Weaken, Opportunity, Threat) analysis. Through reviewing these three theories and analyzing carbon tax, the research question could be answered. Carbon taxing has both positive and negative impacts on China. For positive impacts, the temperature in China would be lowered. More and more people are willing to choose to buy more environmentally friendly cars, sea level rise will slow down, and the pace of China's energy transition will accelerate. For negative impacts, consumption in the domestic market would slow down, low-income families would be hard to maintain daily life, net export would decrease, and the pace of economic growth would become slow. Based on the analysis, the study concludes that China should not apply carbon taxation since the negative impact outweighs the positive impact. If China wants to apply carbon tax, cash transfer programs can mitigate negative impacts such as the increased financial burden on lowincome families.

This study specifically analyzed the impact of a carbon tax in many ways, including the environment, society, and government, which gives people a comprehensive understanding of carbon taxes. This study is being used as a reference when the Chinese government is thinking about improving the environment and reducing greenhouse gas emissions. Also, the study could help provide more insight into carbon taxes if some people research carbon taxes. There is a problem in this study that it only contains SWOT analysis, which is just a qualitative study. If the study included more quantitative models to analyze the extent of the impact on China, the results would be more useful and clearer. However, this study can still be applied in future studies. Scientists can use this research to study how to solve environmental problems.

\section{REFERENCES}

[1] "How Well-off Is China's Middle Class?" ChinaPower Project, 29 Oct. 2020, chinapower.csis.org/china-middle-class/. "Pricing Carbon." World Bank, www.worldbank.org/en/programs/pricingcarbon\#CarbonPricing

[3] Nunez, Christina. "Carbon Dioxide in the Atmosphere Is at a Record High. Here's What You Need to Know." Environment, National Geographic, 3 May 2021, www.nationalgeographic.com/environment/article/ greenhouse-gases.
[4] Brenner, Mark, et al. "A Chinese Sky Trust?" Energy Policy, vol. 35, no. 3, 2007, pp. 17711784., doi:10.1016/j.enpol.2006.04.016.

[5] Dissou, Yazid, and Muhammad Shahid Siddiqui. "Can Carbon Taxes Be Progressive?" Energy Economics, vol. 42, 2014, pp. 88-100., doi:10.1016/j.eneco.2013.11.010.

[6] Brenner, Mark, et al. "A Chinese Sky Trust?" Energy Policy, vol. 35, no. 3, 2007, pp. 1771-1784., doi:10.1016/j.enpol.2006.04.016.

[7] Liang, Qiao-Mei, and Yi-Ming Wei. "Distributional Impacts of Taxing Carbon in China: Results from THE CEEPA MODEL." Applied Energy, vol. 92, 2012, pp. 545-551., doi:10.1016/j.apenergy.2011.10.036.

[8] Liang, Qiao-Mei, et al. "Assessing the Distributional Impacts of Carbon Tax among Households across Different Income Groups: The Case of China." Energy \& Environment, vol. 24, no. 7-8, 2013, pp. 1323-1346., doi:10.1260/0958$305 \times .24 .7-8.1323$.

[9] Dissou, Yazid, and Muhammad Shahid Siddiqui. "Can Carbon Taxes Be Progressive?" Energy Economics, vol. 42, 2014, pp. 88-100., doi:10.1016/j.eneco.2013.11.010.

[10] Guo, Youxia. "DISTRIBUTIONAL EFFECTS OF A CARBON TAX ON URBAN AND RURAL HOUSEHOLDS OF CHINA." (2018).

[11] Wu, Jie, et al. "Understanding the Economic Impact of Interacting Carbon Pricing and Renewable Energy Policy in China." Regional Environmental Change, vol. 20, no. 3, 2020, doi:10.1007/s10113-020-01663-0.

[12]Li, Yu et al. "A new assessment of modern climate change, China-An approach based on paleoclimate." Earth-Science Reviews 177, 2018, pp. 458-477.

[13] Jiao, B. et al. "Research on China's Energy Transition Strategy in the Context of Carbon Neutrality Based on SWOT.", 2021.

[14] Jonathan M. Harris, Brian Roach, Anne-Marie Codur, The Economics of Global Climate Change, 2017, pp. 6-7.

[15] Zhuang, Xiaohong, et al. "Research on the Efficiency and Improvement of Rural Development in China: Based On TWO-STAGE Network SBM Model." MDPI, Multidisciplinary Digital Publishing Institute, 8 Mar. 2021, www.mdpi.com/2071-1050/13/5/2914/htm. 
[16] "China Gini Coefficient." CEIC, www.ceicdata.com/en/china/resident-incomedistribution/gini-coefficient.

[17] "A Whole New Class." CKGSB, english.ckgsb.edu.cn/knowledges/lower-middleclass-china/.

[18] Statistical Communiqué of the People's Republic of China on the 2020 National Economic and Social Development, www.stats.gov.cn/english/PressRelease/202102/t20 210228_1814177.html.

[19] Jos G.J. Olivier et al., European Commission's Joint Research Centre, 2014. "Trends in global CO2 emissions: 2014 Report" http://edgar.jrc.ec.europa.eu/news_docs/jrc-2014trends-in-global-co2-emissions-2014-report93171.pdf

[20] Yunshi Wang, Daniel Sperling, Gil Tal, Haifeng Fang, China's electric car surge, Energy Policy,vol. 102, 2017, pp. 486-490, ISSN 0301-4215,DOI: https://doi.org/10.1016/j.enpol.2016.12.034. 